\title{
Enablers and Mechanisms: Practices for Achieving Synergy with Business Analytics
}

\author{
Ida Asadi Someh \\ Faculty of Business and Economics \\ The University of Melbourne \\ ida.asadi@unimelb.edu.au \\ Michael Davern \\ Faculty of Business and Economics \\ The University of Melbourne \\ m.davern@unimelb.edu.au
}

\author{
Barbara Wixom \\ Center for Information Systems Research \\ MIT Sloan School of Management \\ bwixom@mit.edu \\ Graeme Shanks \\ Department of Computing and Information Systems \\ The University of Melbourne \\ gshanks@unimelb.edu.au
}

\begin{abstract}
Business Analytics (BA) systems use advanced statistical and computational techniques to analyze organizational data and enable informed and insightful decision-making. BA systems interact with other organizational systems and if their relationship is synergistic, together they create higher-order BAenabled organizational systems, which have the potential to create value and gain competitive advantage. In this paper, we focus on the enablers and mechanisms of synergy between BA and other organizational systems and identify a set of organizational practices that underlie the emergence of BA-enabled organizational systems. We use a case study involving a large IT firm to identify the organizational practices associated with synergistic relationships that lead to the emergence of higherorder BA-enabled organizational systems.
\end{abstract}

\section{Introduction}

Managers rely on BA systems ${ }^{1}$ to gain insights from organizational data to make better decisions and compete successfully with their rivals. BA systems use analytical tools and techniques to analyze organizational data, generate insights and visualize the insights to improve organizational decisionmaking. Insights from BA systems enable organizational decision-makers to take competitive actions that differentiate them from their rivals. Industry studies emphasize the significance of these systems to managers $[1,2,3,4,5,6]$.

\footnotetext{
1 We use BA to represent both Business Analytics and Business intelligence [5].
}

Despite the importance of BA systems to managers [6, 7], research on business value of BA systems is still emerging and there is limited understanding of how BA systems contribute to business value. Recent business value of IT literature highlights the role of synergy in generating value from IT systems $[8,9]$. IT systems interact with other organizational systems, and if their relationship is synergistic, together they create higher-order ITenabled organizational systems. IT-enabled organizational systems can create business value and contribute to competitive advantage $[9,10,11]$.

In recent years, several theoretical models have been proposed to explain how business value is created from BA systems [2, 12, 13, 14, 15]. Although [14] and [15] highlight the role of crossunit synergies in sharing data and achieving value from BA systems, the concept of synergy still lacks theoretical development and elaboration in general and in the context of BA systems. Here, we build on our previous work [24] which theorizes about the enablers and mechanisms of synergy between BA and other organizational systems. We argue that the specific organizational practices through which BA systems interact and synergize with other organizational systems to generate business value are not well known or understood. Hence, we seek to answer the following research question: What are the organizational practices that contribute to achieving synergy between business analytics and other organizational systems?

To address this question, we focus on understanding how the enablers and mechanisms of synergy lead to the emergence of higher-order BAenabled organizational systems. BA systems comprising data scientists, analytical tools and insight generation processes interact with other 
organizational systems such as marketing, sales, HR and finance. If the interaction between the two systems is synergistic, together they will form higherorder BA-enabled organizational systems. BAenabled organizational systems (e.g. BA-enabled marketing systems) leverage data and analytics to accomplish tasks, take competitive actions and make strategic decisions. In particular, we use an in-depth case study to identify the organizational practices that form the enablers and mechanisms of synergy. This is an important contribution to comprehensively and concretely defining synergy within the context of BA systems.

There are two motivations for our work. First, there is significant interest in BA systems both in academia and practice. BA systems were ranked as the number one IT investment for six years in a row from 2009 to 2014 [8]. BA was identified as the first technical priority for CEOs and one of the four major technology trends by IBM in 2012 [6, 15]. However, there is little theoretical explanation of how BA systems interact with other organizational systems and create BA-enabled organizational systems. Second, the concept of synergy has had limited consideration in IS literature, and its merits still remain largely unexplored [18]. In this paper, we study the role of synergy in creating BA-enabled organizational systems.

The paper is structured as follows. First, we discuss the concept of synergy, drawing upon systems theory as its theoretical underpinning. Next, we present our theoretical framework and then discuss the case study research approach used in the study. Following that we describe the case study and identify the practices related to the enablers and mechanisms of synergy. Finally, we discuss implications for researchers and practitioners, and suggest areas for future research.

\section{Synergy}

The concept of synergy is theoretically grounded in systems theory. Systems theory deals with systems taken as a whole, rather than individual parts [19]. The whole system, derived from the synergistic interaction of the parts, equals the sum of its parts plus the new properties emerging from their interactions [20]. The new properties derived from the subsystem's interactions are called emergent properties. The emergent properties of a collective system can be perceived and measured distinct from the properties of the subsystems in isolation [21].

An organization, with respect to systems theory, can be conceptualized as a set of interconnected systems [22]. This contrasts with the Resource Based View (RBV) which views an organization as a bundle of resources [23]. The use of systems theory helps to model the interaction among resources, which is not possible using RBV theory.

\section{Theoretical Framework}

The theoretical framework (presented in Figure 1) shows that a synergistic relationship leads to synergistic outcomes (emergent properties of higherorder BA-enabled Organizational Systems [22]). The framework is synthesized from information systems literature that has theorized about synergy.

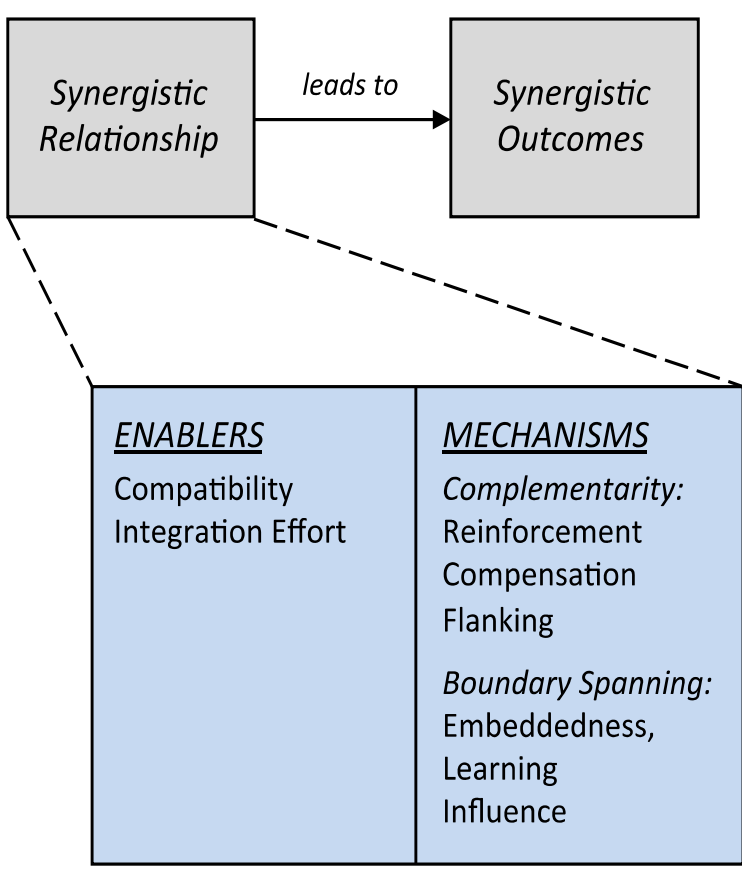

Figure 1. Theoretical Framework

The focus of this study is on synergistic relationship.

\subsection{Synergistic Relationship}

A Synergistic Relationship is formed by the enablers and mechanisms of synergy [24]. The enablers of a synergistic interaction are the necessary precursors that facilitate the emergence of new capabilities. They represent the context within which mechanisms can have effect. Mechanisms are the activities that take place among systems to realize their potential synergy.

3.1.1. Synergy Enablers. Compatibility and Integration Effort enable synergy between IT systems 
and other organizational systems [8, 9]. Compatibility is the degree to which systems fit with each other and is achieved when systems are able to seamlessly work together. Integration Effort is the extent to which management seeks to bring the systems together and directs their interaction congruent with organizational goals $[8,9]$. It is the strategic direction of management in bringing together all parts of an organization into an integrated whole and planning how the interaction among systems will serve the organization.

\subsubsection{Synergy Mechanisms. Synergy} mechanisms are the activities that take place among systems to realize their potential synergy, and they are of two types: complementarity mechanisms and boundary spanning mechanisms.

Complementary mechanisms are the activities by which systems are combined to enhance and complement each other's functionalities. These mechanisms are theoretically grounded in the economic theory of complementarities [25]. Complementarity relations arise from differences among systems and are realized when systems mutually support and enhance each other's efficiency [26]. System complementarity has been frequently described in the IS literature as the main source of synergy [9, 24, 25, 26]. Complementary mechanisms for realizing synergy include Reinforcement, Flanking, and Compensation mechanisms.

Reinforcement mechanisms occur when systems consistently work with each other, add crucial contributions to each other and enhance each other's organizational impact $[27,28]$. For example, collaboration between different systems can help to enhance the functionality of one individual system.

Flanking mechanisms occur when one system creates conditions that enable another system to improve its effectiveness [29]. For example, when a system lacks the knowledge to perform a task, training can act as a flanking mechanism to enhance its effectiveness.

In the case of compensation mechanisms, one system blocks or diminishes the negative effects of another system with respect to organizational goals $[27,28]$. For example, incentives can act as a compensating practice to address the misalignment of human system activities with organizational goals and enhance their efficiency [31].

Boundary spanning mechanisms refer to the activities that help systems to bridge the knowledge gap between domains. These mechanisms help to create a shared field among systems, in which they can cross their boundaries to collaborate and exchange knowledge. Boundary spanning mechanisms assist complementary systems to realize a shared language for collaboration. Therefore, boundary spanners play a critical role in stimulating synergistic interactions among systems [32]. Embeddedness, Learning and Influence are the three types of boundary spanning mechanisms.

Embeddedness occurs when a firm creates social ties with another based on familiarity, trust and commitment [33]. These social ties connect systems from different contexts to collaborate, share knowledge and develop social capital. This mechanism facilitates crossing system boundaries and interacting with other communities of practice, which leads to synergistic outcomes.

Learning is a boundary spanning mechanism that is based on social information processing theory and organizational learning theory [32]. The social environment provides an immediate source of information for individuals who can process and act on the information they collect. This mechanism helps the systems to sense the environment and exploit the opportunities offered to them. It also can help them to better understand each other's values and norms and lead to their synergistic interaction [32].

Finally, the influence mechanism, grounded in institutional theory, forces organizations and individuals to conform to norms, traditions and social expectations [32]. Based on this mechanism, dominant systems can force their interacting partners to comply with their rules, norms and values. Further, systems can influence each other to develop a shared mental model through their interactions and become aware of each other's plans and reactions.

\subsection{Synergistic Outcomes}

Synergistic Outcomes refers to the emergent properties of BA-enabled organizational systems. The interaction among systems will give rise to the emergence of new properties, which cannot be reduced to individual systems [8, 9]. For example, "the ability to cross-sell based on customer behavior analysis" is a joint capability that emerges from the interaction between BA and CRM systems.

\section{Research Method}

In order to understand how synergy is realized between business analytics systems and other organizational systems, we use a single case study research approach. Case studies are useful for investigating contemporary phenomena within their organizational context [34]. They provide a rich and 
detailed description of the phenomena and describe how and why outcomes occur. Single case studies are appropriate when they are unique or revelatory [34]. The case study reported in this paper is revelatory as the business analytics initiatives and organizational changes implemented were novel and critical to obtaining business value. The unit of analysis is the business analytics function within a large IT firm (TechCo).

Data collection involved semi-structured interviews and other publicly available material. We conducted a total of thirteen interviews with senior managers and BA experts. Details about the roles of interviewees are listed in Table 1. Each interview lasted about one hour. All interviews were recorded and transcribed. In addition to the interviews, a significant amount of publicly available material about business analytics within the organization was sourced from various media outlets and industry presentations.

The interview protocol was based on concepts in our theoretical framework. However, to generate rich insights and elicit a range of organizational practices, we asked generic questions regarding the interaction between the BA groups and other business functions (as opposed to explicit questions about enablers and mechanisms). This helped us to avoid directing our interviewees in any particular direction. Our interview questions focused on the evolution of analytics, best practices, failures, current status of analytics in each business function and how interactions between the BA and business groups has helped them to develop data-driven business units.

Table 1. Interviewees and their Roles

\begin{tabular}{|l|l|}
\hline Area & Roles \\
\hline $\begin{array}{l}\text { Information } \\
\text { Technology } \\
\text { (6 interviews) }\end{array}$ & $\begin{array}{l}\text { Vice President, Director of Data } \\
\text { Science, Director of Enterprise } \\
\text { Data Services, Business } \\
\text { Analytics Manager }\end{array}$ \\
\hline $\begin{array}{l}\text { Human } \\
\text { Resources } \\
\text { (3 interviews) }\end{array}$ & $\begin{array}{l}\text { Business Analytics Manager, } \\
\text { Staffing Manager }\end{array}$ \\
\hline $\begin{array}{l}\text { Marketing } \\
(2 \text { interviews) }\end{array}$ & $\begin{array}{l}\text { Business Analytics Program } \\
\text { Manager }\end{array}$ \\
\hline $\begin{array}{l}\text { Sales } \\
\text { (1 interviews) }\end{array}$ & Business Analytics Program \\
\hline $\begin{array}{l}\text { Finance } \\
(1 \text { interviews })\end{array}$ & Director of Business Analytics \\
\hline
\end{tabular}

Case study data was analyzed using thematic content analysis to identify common patterns and themes emerging from the data [35].

\section{Case Study}

Here, we discuss the case study organization and analysis.

\subsection{Case Study Context}

The case study organization was a large global IT firm. TechCo sells a diverse range of IT products, including a growing number of BA solutions. TechCo was committed to becoming a data-driven organization and used BA internally to improve decision making across the organization.

There were two types of BA groups within TechCo: a central BA group that operated under IT and local BA groups that were aligned to business functions. The central group focused on enabling analytics in terms of data and tools across the organization and provided leadership to promote BA at a large scale. On the other hand, each business function, such as Human Resources (HR), Finance, Sales and Marketing had their own BA group to meet localized needs expeditiously. These local BA groups were aligned to specific business processes and supported decision making within that function.

\subsection{Case Study Analysis}

The case study analysis revealed several organizational practices for each of the enablers and mechanisms. These practices help us extend our understanding of how synergy manifests in an organizational context. Detailed discussion of each of the eight enablers and mechanisms of synergy, together with evidence from the interviews, is provided below.

Compatibility: Compatibility between BA and other organizational systems occurs when systems fit together and have a shared language and common data definitions exist across the organization. One way in which Compatibility was enabled at TechCo was through master data management practices. The enterprise data services team worked closely with different stakeholders to create consistent data definitions across the organizations. They recognized that if BA and other organizational systems did not agree upon the definitions, they would not be able to work together. 
"We work very closely [with enterprise data services]. They have been for quite some time working on data management and trying to get the business stakeholders on the same page and getting them involved. For example, one of the things they were trying to do is come up with a universal definition of churn." - Director of Data Science

To create the agreement regarding data definitions, enterprise data services brought stakeholders together and facilitated discussions among them.

"What we've learned is that the most difficult master data cuts across all [organizational processes]. We learned over time that to treat something as a master data object, we will bring together a council of people, who each have a dog in the fight. We help them outline a data topic or a data issue and present options to help them align themselves." - Director of Enterprise Data Services

Integration Effort: Integration Effort is influenced by management practices to support and direct the use of BA systems within organizations. TechCo's CEO was an early adopter of BA within the company. Further, he clearly communicated a vision for the role of data.

"Our [CEO] says very consistently within the company that we want to be a data driven organization." - Director of Business Intelligence

To integrate BA into the "muscle" of the organization, TechCo management supported a variety of change practices, such as hiring data scientists and creating a data science career path. Hiring managers found that having data science specific job titles and subsequent data science opportunities were critical to attract top talent.

"We decided to work with HR, and we created a data science job code under engineering with different levels and job descriptions." - Director of Data Science

Reinforcement: Reinforcement refers to practices that occur between BA and other organizational systems in a way that they add to each other's functionalities and enhance each other. We identified the reinforcement mechanism at TechCo when business people from one function expanded the scope of their BA project after seeing first-hand what could be done by another group using shared data.
"After we had started to mine the data, our approach was that the solution would be so much better and so much more robust if we could bring in additional data sources." Once we added those additional data sources, everyone is like, "Oh, look, there is an innovative solution we just came up. The outcome was totally from the collaboration between different groups." - Director of Data Science

Another practice that enhances and reinforces business decision-making is embedding and automating insights within business processes so that the business people can frequently use them. At TechCo, a Marketing Business Analytics Program Manager identified a way to incorporate market studies into strategic decision-making processes in a repeatable way. He valued being able to deliver an important tool to Marketing decision makers on a monthly, weekly, and even daily basis.

Flanking: Based on this mechanism, BA systems provide discrete inputs to the business. At TechCo, an important flanking mechanism was the consultative services that the central BA team provided to different business functions:

"What we typically would do, we'll engage with the actual analytics team within business functions that are behind a major initiative and help them to spin up something that they might not have known is possible. Then we hand that off to them." - Director of Business Intelligence

Compensation: The interacting systems use the compensation mechanism to reduce the negative impacts of each other. At TechCo, the BA team leveraged the BA reports to expose data quality problems:

"My job right now is to make data quality understood across the enterprise and expose it so that the business can become owners of their own data. Today the business is still in that transition where they say, "I'm just a user of the data. IT owns the data." The goal and the expectation is that we need to transition to say, "No, no, you are the creators of the data. It's yours because you own the process. The data is a by-product of the process." Director of Enterprise Data Services.

Embeddedness: Embeddedness mechanisms create social ties between people from different organizational systems. The social ties help individuals with common special interests to connect 
from across the organization and develop social capital. These social ties can then be leveraged for knowledge sharing and collaboration.

The TechCo Enterprise Data Science group managed a data science distribution list to find and connect data scientists across TechCo.

"About four years ago I started a data science distribution list in which people self-opted. Before we had the official title called data scientist, we had people included on that list from different communities. As they [attended internal data science] summits, they self-identified themselves as data scientists. So that's how it started. Now all announcements go out to the list." - Director of Data Science

Online communities helped people across the organization to connect and share ideas with the intent of creating innovative insights through crossbreeding.

"We intentionally have not organized our selfservice community into sections. You're going to see someone asking a Marketing question, and a set of Finance people who are part of that community will hear that question, too. Why we are resistant to [sectioning the community] is that a positive side effect of it is cross pollination. If we start creating silos, we feel like we are being counter-productive." - Director of Business Intelligence

Another practice relating to embeddedness is relying on former functional employees. TechCo repositioned a former product developer to generate advanced insights using the same product that he previously developed. Apart from the product knowledge, the advantage of this approach was that the insights manager was very well connected to product team members and could utilize his network to solve problems.

"I spent about 12 years in product teams that made the previous versions of this tool. Now I am my own customer. When I have a problem, I know who to call and ask for fixing it."- Business Analytics Manager

Learning: Learning is a boundary spanning mechanism, which helps BA and other organizational systems cross the knowledge gaps between them. This can happen by interacting with different groups and sensing the opportunities in the environment.
TechCo BA teams used internal online businessrelated communities to learn about business requirements. For example, the BA team who most closely supported HR leveraged the HR social platform as a way to gauge sentiment.

"For getting the requirements, or merging needs and themes, we pay attention to the HR professionals Yammer group, to see what they're talking about." HR Director of Business Intelligence

Online communities also provided a virtual environment for BA users to share knowledge and to learn from each other across the organization.

"The Yammer groups helped to have people coach other people about what they did [with BA]. The question is, "has anyone tried mashing up this data with that data before? Once you get a critical mass, [people across the community contribute answers]." - Director of Enterprise Data Services??

To further facilitate the learning activities, TechCo used gamification techniques to increase employee participation within the online communities.

"When we created the initial communities, we incented quite a few people across the company [to participate]. We even offered games... Who has the best idea? It wasn't who had the best finance idea. It was who had the best idea. And ideas popped up from Marketing, they popped up from Sales, they popped up from everywhere across the company." Director of Business Intelligence

Influence: This mechanism helps BA people influence the thinking and behavior of people from other organizational units. TechCo's BA group tried to influence employees and change mindsets in a variety of ways. For example, they used marketing techniques, such as segmentation, campaign planning and surveys to encourage users to adopt new BA tools and techniques.

"I'm using my sales and marketing skills.... You have to use them now to help folks understand how to use these [BA] tools." - Vice President IT

TechCo also used broadcast mechanisms to reach different stakeholders and to create visibility and awareness about BA-related activities that took place across the organization. 
"We've got broadcast mechanisms like target emails and monthly newsletters. We have personabased messages that go out as well. We are constantly looking to harvest... good examples of people being successful with BI, and then we amplify that out. We are building awareness and visibility and trying to get people thinking, "Hey, somebody was successful doing this, I might be interested in it." - Director of Business Intelligence

\subsection{Summary of Finding}

We explored the organizational practices associated with enablers and mechanisms of synergy at TechCo. The enablers and mechanisms of synergy are largely unexplored in the context of BA systems both theoretically and practically. Current information systems literature has studied fragmented aspects of synergy such as the role of organizational learning in achieving value from BA systems [14], embeddedness of BA systems within organizational technologies and processes [36] and reinforcement through sharing of data across multiple business unit $[15,16]$. However, a comprehensive and practical view on synergy is still missing. Our study extends the theoretical underpinning of synergy proposed in [24] to the relationship between BA and other organizational systems using a single case study approach. In particular, our findings translate the theoretical concepts into practice and create a more tangible view on synergy.

Table 2 presents a summary of our findings for enablers of synergy between BA and other organizational systems respectively. Consistent with our definition of enablers in Section 3.1, we identified organizational factors or properties that facilitated the realization of synergy at TechCo. Compatibility was manifested through shared language and common data definitions. Integration Effort was manifested through management support and sponsorship and a clear vision on the role of analytics in achieving organizational goals. Although current literature has provided evidence for the importance of management involvement in achieving value from BA systems $[37,38,39,40]$, Compatibility and Integration Effort are two theoretical constructs and their practical meaning for BA systems has not been explored. Our findings extend the literature on business value of IT systems $[9,10]$ that has only focused on studying enablers of synergy between IT assets and other organizational systems.
Table 2. Summary of Findings for Enablers

\begin{tabular}{|c|l|}
\hline Enablers & \multicolumn{1}{c|}{ Organizational Factors } \\
\hline Compatibility & $\begin{array}{l}\text { - Shared language } \\
\text { - Common data definitions }\end{array}$ \\
\hline $\begin{array}{c}\text { Integration } \\
\text { Effort }\end{array}$ & $\begin{array}{l}\text { - Senior management } \\
\text { sponsorship } \\
\text { - A clear vision on the role of } \\
\text { analytics }\end{array}$ \\
\hline
\end{tabular}

We identified several organizational practices associated with complementary and boundary spanning mechanisms of synergy at TechCo. These findings are summarized in Table 3. Organizational practices that underlie Reinforcement, Flanking and Compensation mechanisms, demonstrate how BA systems can complement other organizational systems in practice. Existing literature on these mechanisms $[29,31]$ is theoretical and abstract and does not apply to the synergistic relationship between BA systems and other organizational systems. Our findings provide practical pathways for how BA can complement other organizational systems and realize potential synergies.

Our case study analysis also revealed several organizational practices associated with boundary spanning mechanisms. Although prior literature has discussed the role of organizational learning and embeddedness in achieving value from BA systems [1, 14, 36, 37, 38], little attention has been paid to how BA people and technologies belonging to a different and particular community of practice interact with other communities within an organizational setting [43]. BA people and technologies learn from other communities of practice, become embedded in their social networks and processes and finally influence them to become more analytical and data-driven in their actions and decisions [24, 40]. Our findings extend the existing scattered literature by theorizing about the role of boundary spanning mechanisms for achieving synergy, integrating different boundary spanning mechanisms, and providing a clear set of practices that can help BA people span their boundaries and influence other communities. 
Table 3. Summary of Findings for Mechanisms

\begin{tabular}{|c|c|}
\hline Mechanisms & Organizational Practices \\
\hline \multicolumn{2}{|c|}{ Complementary Mechanisms } \\
\hline Reinforcement & \begin{tabular}{|l} 
- Automation of insights \\
- Product co-development \\
- Breaking down data silos
\end{tabular} \\
\hline Flanking & $\begin{array}{l}\text { - Consultative services } \\
\text { - Setting up shared templates }\end{array}$ \\
\hline Compensation & - Improving data quality \\
\hline \multicolumn{2}{|c|}{ Boundary Spanning Mechanisms } \\
\hline Learning & $\begin{array}{l}\text { - Providing an outside-in } \\
\text { perspective } \\
\text { - Knowledge sharing through } \\
\text { online communities } \\
\text { - Gamification } \\
\text { - Learning from tracking } \\
\text { adoption and usage }\end{array}$ \\
\hline Embeddedness & $\begin{array}{l}\text { - Creating data science } \\
\text { distribution lists } \\
\text { - Online communities that } \\
\text { connect people from different } \\
\text { areas } \\
\text { - Former functional employees }\end{array}$ \\
\hline Influence & $\begin{array}{l}\text { - Marketing skills to promote BA } \\
\text { - Broadcast mechanisms to } \\
\text { create awareness }\end{array}$ \\
\hline
\end{tabular}

\section{Discussion}

The case study revealed organizational practices regarding enablers and mechanisms of synergy. These practices help to explain how synergy can unfold in an organizational context and lead to creation of BA-enabled organizational systems. The concept of synergy is under-developed in information systems and broader management literature. Our conceptualization of synergy as a relationship extends the current literature on synergy that has mainly investigated the outcomes of synergy or has studied the fragmented aspects of synergy $[8,9,24$, $27,30]$.

\subsection{Implications for Researchers}

This study has implications for understanding both BA systems and synergy in IS more broadly. By their very nature, BA systems contribute value through their interaction with other organizational systems. Synergy is thus fundamental to understanding how BA systems function successfully in organizations $[9,16,39]$. We present a theoretical framework for synergy and the underlying enablers and mechanisms through which a synergistic relationship is achieved, in the context of BA systems. In documenting and classifying illustrative practices in accordance with this framework, we instantiate the concept of synergy as a relationship from the abstract to the concrete. Given that the concept of synergy has only had limited consideration in the IS literature, by mapping from concept to practice we also provide clarity to the definition of the underlying enablers and mechanisms.

By analyzing specific practices through the lens of our synergy framework, we also evidence how systems theory helps understand the interaction among organizational resources in a way that is not possible using RBV. For example, consider the practices of "Master data management" (Enabler: Compatibility) and "Improving data quality" (Mechanism: Compensation). In RBV these two practices would be viewed as managing a resource to maximize its value in isolation. From the perspective of our synergy framework, with its grounding in systems theory, we see a broader purpose to these practices. In the case of "Master data management," we see it as enabling different organizational systems to more effectively communicate and share data, thereby generating value beyond that contributed by any one system or resource alone. In the case of "Improving data quality," the benchmark for quality is from the perspective of the interacting systems, rather than a system or resource in isolation. In situations where the costs and benefits of improving data quality are unequally distributed across organizational systems, the additional explanatory power we provide is particularly evident. The noninteracting resource perspective of RBV would not be able to easily explain the more comprehensive investment in organizational practices to improve data quality that are readily seen as justifiable from our systems theory-based concept of synergistic relationship [10].

Our documenting of the particular practices that correspond to each enabler and mechanism provides a foundation for future empirical research. For example, it can inform the development of appropriate constructs for subsequent cross-sectional survey research exploring the effects of the synergistic relationship between BA systems and other organizational systems, and ultimately how the synergistic relationship may lead to business value.

\subsection{Implications for Practitioners}

BA systems entail sizable organizational investment. We document an array of practices that provide concrete guidance to practitioners and organizations 
seeking to reap the benefits of investments in BA systems through establishing a synergistic relationship with other organizational systems. More specifically, we demonstrate the interplay between organizational and technical elements in the practices that comprise these synergistic interactions. Importantly, our theory also serves to highlight the goals or purposes of the practices in terms of achieving a synergistic relationship. By enhancing understanding of the goals or purposes to which certain practices may be directed, we provide additional motivation and justification for the adoption of such practices. Furthermore, this understanding ensures that in implementing these practices, the potential for developing a synergistic relationship between BA systems and other organizational systems is not overlooked, and is in fact leveraged.

\section{Conclusion}

This paper focuses on the enablers and mechanisms of synergy between BA and other organizational systems and identifies a set of organizational practices that underlie the emergence of BA-enabled organizational systems. There are two limitations to the study. First, it is based on a single case study. Although the TechCo case study is revelatory, more case studies and other research methods are required to better understand the organizational practices that create synergy. Second, in this study we focus strongly on the enablers and mechanisms of synergistic relationships. Further research is required to better understand how and why these enablers and mechanisms lead to emergent higher-order BAenabled Organizational Systems, which in turn lead to organizational value.

\section{References}

[1] T. H. Davenport and J. G. Harris, Competing on Analytics: The New Science of Winning. Harvard Business School Press, 2007.

[2] B. Wixom, B. Yen, and M. Relich, "Maximizing Value from Business Analytics.," MIS Q. Exec., vol. 2013, no. June, pp. 61-71, 2013.

[3] A. McAfee and E. Brynjolfsson, "Big Data. The management revolution," Harvard Buiness Rev., vol. 90, no. 10, pp. 61-68, 2012.

[4] S. LaValle and E. Lesser, "Big data, analytics and the path from insights to value," MIT Sloan Manag. Rev., 2013.

[5] H. Chen, R. Chiang, and V. Storey, "Business Intelligence and Analytics: From Big Data to Big
Impact," $M I S Q$. , vol. 36, no. 4, pp. 1165-1188, 2012.

[6] T. H. Davenport, "The New World of ' Business Analytics ," no. March, 2010.

[7] J. Hagerty, R. L. Sallam, and J. Richardson, "Magic Quadrant for Business Intelligence Platforms," Gart. Doc., 2012.

[8] L. Kappelman, E. Mclean, V. Johnson, and N. Gerhart, "The 2014 SIM IT Key Issues and Trends Study," MIS Q. Exec., vol. 13, no. 4, pp. 237-263, 2014.

[9] S. Nevo and M. Wade, "Firm-Level Benefits of IT-enabled Resources: A Conceptual Extension and an Empirical Assessment," J. Strateg. Inf. Syst., vol. 20, no. 4, pp. 403-418, 2011.

[10] S. Nevo and M. Wade, "The Formation and Value of IT-enabled Resources: Antecedents and Consequences of Synergistic Relationships," MIS $Q$., vol. 34, no. 1, pp. 163-183, 2010.

[11] A. Bharadwaj, "A Resource-Based Perspective on Information Technology Capability and Firm Performance: An Empirical Investigation," MIS $Q$. , vol. 24, no. 1, p. 169, Mar. 2000.

[12] S. Dong, S. X. Xu, and K. X. Zhu, "Research Note--Information Technology in Supply Chains: The Value of IT-Enabled Resources Under Competition," Inf. Syst. Res., vol. 20, no. 1, pp. 18-32, Feb. 2009.

[13] T. T. Tamm, P. B. B. P. B. B. Seddon, and G. G. G. G. Shanks, "Pathways to Value from Business Analytics," in ICIS 2013 Proceedings, 2013, vol. 4, pp. 2915-2930.

[14] G. Shanks and N. Bekmamedova, "Achieving Benefits with Business Analytics Systems: An Evolutionary Process Perspective," J. Decis. Syst., vol. 3, no. November, pp. 37-41, 2012.

[15] B. Dinter and R. Winter, "Information logistics strategy - Analysis of current practices and proposal of a framework," Proc. 42nd Annu. Hawaii Int. Conf. Syst. Sci. HICSS, 2009.

[16] G. Lahrmann, R. Winter, and B. Dinter, "Information Logistics as a Conceptual Foundation for Enterprise-Wide Decision Support," J. Decis. Syst., vol. 19, no. 2, pp. 175200, 2010

[17] IBM, "The 2012 IBM Tech Trends Report," 2013.

[18] G. Schryen, "Revisiting IS business value research: what we already know, what we still need to know, and how we can get there," Eur. $J$. Inf. Syst., vol. 22, no. 2, pp. 139-169, 2013.

[19] A. Burton-Jones, E. R. Mclean, and E. Monod, "Theoretical perspectives in IS research: from variance and process to conceptual latitude and conceptual fit,” Eur. J. Inf. Syst., pp. 1-16, 2014.

[20] R. L. Ackoff, "Towards a System of Systems 
Concepts," Manage. Sci., vol. 17, no. 11, pp. 661671, 1971.

[21] P. A. Corning, "The re-emergence of emergence: A venerable concept in search of a theory," Complexity, vol. 7, no. 6, pp. 18-30, 2002.

[22] F. E. Kast and J. E. Rosenzweig, "General systems theory: applications for organization and management.," Acad. Manag. J., vol. 11, no. 7, pp. 32-41, Jul. 1981.

[23] J. Barney, "Firm Resources and Sustained Competitive Advantage," J. Manage., vol. 17, no. 1, p. 99, Mar. 1991.

[24] I. Asadi Someh and G. Shanks, "The Role of Synergy in Achieving Value from Business Analytics Systems," in International Conference on Information Systems(ICIS), 2013.

[25] P. Milgrom and J. Roberts, "Complementaries and Fit Strategy, Structure, and Organizational Change in Manufacturing," J. Account. Econ., vol. 19, pp. 179-208, 1995.

[26] H. Tanriverdi, "Performance Effects of Information Technology Synergies in Multibusiness Firms," MIS Q., vol. 30, no. 1, pp. 57-77, 2006.

[27] V. Grover and R. Kohli, "Cocreating IT Value: New Capabilities and Metrics for Multifirm Environments," MIS Q., vol. 36, no. 1, pp. 225$232,2012$.

[28] N. Melville, K. Kraemer, and V. Gurbaxani, "Review: Information Technology and Organizational Performance: An Integrative Model of IT Business Value," MIS Q., vol. 28, no. 2, pp. 283-322, 2004.

[29] T. W. Ferratt, J. Prasad, and H. G. Enns, "Synergy and Its Limits in Managing Information Technology Professionals," Inf. Syst. Res., vol. 23, no. 4, pp. 1175-1194, Mar. 2012.

[30] M. Wade and J. Hulland, "Review: The ResourceBased View and Information Systems Research: Review, Extension, and Suggestions for Future Research," MIS Q., vol. 28, no. 1, pp. 107-142, 2004.

[31] J. Horgan and P. Mühlau, "Human Resource Systems and Employee Performance in Ireland and the Netherlands: A Test of the Complementarity Hypothesis," Int. J. Hum. Resour. Manag., vol. 17, no. 3, pp. 414-439, Mar. 2006.

[32] V. Venkatesh and H. Bala, "Adoption and Impacts of Interorganizational Business Process Standards: Role of Partnering Synergy," Inf. Syst. Res., vol. 23, no. 4, pp. 1131-1157, 2012.

[33] M. Granovetter, "Economic Action and Social Structure: The Problem of Embeddedness," Am. J. Sociol., vol. 91, no. 3, pp. 481-510, 1985.
Methods, vol. 5, no. 5. Sage Publications, 2009.

[35] M. B. Miles and A. M. Huberman, Qualitative Data Analysis: An Expanded Sourcebook, 2nd Editio. SAGE Publications, 1994.

[36] G. Shanks, N. Bekmamedova, F. Adam, and M. Daly, "Embedding business intelligence systems within organisations," in Frontiers in Artificial Intelligence and Applications, 2012, vol. 238, pp. 113-124.

[37] G. Shanks, N. Bekmamedova, and L. Willcocks, "Business Analytics: Enabling Strategic Alignment And Organisational Transformation," in ECIS, 2012, p. Paper 18.

[38] T. H. Davenport, "Competing on analytics," Harv. Bus. Rev., 2006.

[39] H. Watson and B. Wixom, "The current state of business intelligence," Computer (Long. Beach. Calif)., vol. 40, no. 9, pp. 96-99, 2007.

[40] B. Wixom and H. Watson, "An Empirical Investigation of the Factors Affecting Data Warehousing Success," MIS Q., vol. 25, no. 1, pp. 17-41, 2001.

[41] R. Cosic, G. Shanks, and S. Maynard, "A business analytics capability framework," Australas. J. Inf. Syst., vol. 19, pp. S5-S19, 2015.

[42] M. Z. Elbashir, P. a. Collier, and S. G. Sutton, "The Role of Organizational Absorptive Capacity in Strategic Use of Business Intelligence to Support Integrated Management Control Systems," Account. Rev., vol. 86, no. 1, pp. 155184, 2011.

[43] D. Marchand and J. Peppard, "Why IT Fumbles Analytics?," Harvard Buiness Rev., vol. 91, no. 1, pp. 104-112, 2013.

[44] I. Asadi Someh and G. Shanks, "Emergence of Business Value from Complementary Interactions between Informational and Transactional IT systems," Aust. J. Inf. Syst., vol. 20, pp. 1-15, 2016.

[45] R. Titah and H. Barki, "Nonlinearities between Attitude and Subjective Norms in Information Technology Acceptance: A Negative Synergy?," MIS Q., vol. 33, no. 4, pp. 827-844, 2009. 